\title{
Relieved Air Pollution Enhanced Urban Heat Island Intensity in the Yangtze River Delta, China
}

\author{
Hao Wu ${ }^{1,2}$, Tijian Wang ${ }^{2 *}$, Qin'geng Wang ${ }^{*}$, Nicole Riemer ${ }^{3}$, Yang Cao ${ }^{4}$, Chong Liu ${ }^{2}$, \\ Chaoqun $\mathrm{Ma}^{2}$, Xiaodong $\mathrm{Xie}^{2}$ \\ ${ }^{1}$ School of Environment, Nanjing University, Nanjing 210023, China \\ ${ }^{2}$ School of Atmospheric Sciences, Nanjing University, Nanjing 210023, China \\ ${ }^{3}$ Department of Atmospheric Sciences, University of Illinois at Urbana-Champaign, Urbana, IL 61801, USA \\ ${ }^{4}$ Jiangsu Urban Planning and Design Institute, Nanjing 210024, China
}

\begin{abstract}
The National Air Pollution Control Plan implemented by China in 2013 reduced the concentrations of air pollutants, especially $\mathrm{PM}_{2.5}$ (aerosol particles with an aerodynamic diameter equal to or less than $2.5 \mu \mathrm{m}$ ), between 2014 and 2017 . This reduction in $\mathrm{PM}_{2.5}$ potentially affected the intensity of urban heat islands (UHIs), as the presence of fine particles can influence the energy balance of the earth-atmosphere system. In this study, the effect of the pollution control plan on the UHI intensity in the Yangtze River Delta, China, was investigated via observational analysis and numerical modeling. According to the observational data, the $\mathrm{PM}_{2.5}$ concentrations in the megacities of the Yangtze River Delta, viz., Shanghai, Nanjing, Hangzhou and Hefei, in 2017 were $~ 35 \mu \mathrm{g} \mathrm{m}^{-3}$, showing decreases of approximately $48.36 \%, 28.25 \%, 29.41 \%$ and $32.5 \%$, respectively, compared to 2014. Furthermore, these reductions in the $\mathrm{PM}_{2.5}$ concentration correlated well with the strengthened diurnal intensity (increasing by up to $1 \mathrm{~K}$ ) and the weakened nocturnal intensity (decreasing by up to $1 \mathrm{~K}$ ) of the UHIs. Numerical simulations confirmed that this "seesaw effect" on the UHI intensity was due to the decrease in $\mathrm{PM}_{2.5}$ and the consequent increase in the downward surface shortwave radiation and the outgoing top-of-the-atmosphere longwave radiation. Thus, the Air Pollution Control Plan noticeably affected the UHI intensity by reducing PM $2.5-$ a factor which should be considered in future studies on urban climate and environmental planning.
\end{abstract}

Keywords: $\mathrm{PM}_{2.5}$; Urban heat island; WRF-Chem; Yangtze River Delta.

\section{INTRODUCTION}

Rapid industrialization and urbanization in the last decades have changed land cover, surface albedo and anthropogenic heat flux as well as air pollutant concentrations in China (Xia et al., 2014). These changes have significantly impacted the urban heat island (UHI) effect, which refers to the increased surface temperature over urban areas compared to the surrounding areas (Howard, 1833; Manley, 1958; Oke, 2002). UHI is a local phenomenon and distinct from largescale global warming trends (Jones et al., 1990; Peterson et al., 1999). It affects the boundary layer and the underlying surface energy balance (Lin et al., 2008), as well as wind patterns (Hjelmfelt, 2017), precipitation (Zhong et al., 2017) and sensible heat convection efficiency (Zhao et al., 2014).

\footnotetext{
* Corresponding author.

Tel.: 1-395-200-3593;1-395-180-6857

E-mail address: tjwang@nju.edu.cn (T. Wang);

wangqg@nju.edu.cn (Q. Wang)
}

The UHI also has a significant impact on air pollutants by producing local wind patterns that cause urban centers to suffer even more severe air pollution (Agarwal and Tandon, 2010). Meanwhile, human activities with the growing population result in the increase of air pollutant emissions (Wang et al., 2006). This results in an uneven distribution of air pollutants, including $\mathrm{PM}_{2.5}$, in the urban center and suburban district, which in turn feeds back on the UHI.

Increased population and anthropogenic activities in the urban centers have made $\mathrm{PM}_{2.5}$ (aerosol particles with aerodynamic diameters equal to or less than $2.5 \mu \mathrm{g}$ ), $\mathrm{PM}_{10}$ (aerosol particles with aerodynamic diameters equal to or less than $10 \mu \mathrm{m})$, ozone $\left(\mathrm{O}_{3}\right)$, carbon monoxide $(\mathrm{CO})$, sulfur dioxide $\left(\mathrm{SO}_{2}\right)$ and nitrogen dioxide $\left(\mathrm{NO}_{2}\right)$ well known as the main air pollutants in China in the recent years. $\mathrm{PM}_{2.5}$ is the dominant factor causing hazy weather and the primary atmospheric particulate pollutant (Liang et al., 2014). $\mathrm{PM}_{2.5}$ scatters and absorbs solar radiation and thus affects the climate by changing the energy balance of the earth-atmosphere system (Kaufman et al., 2002; Zhang et al., 2010; Nabat et al., 2014). According to the national observational data collected from 74 big cities in the Bulletin on Environmental 
Conditions in China, annual $\mathrm{PM}_{2.5}$ concentrations in these cities ranged from $26-160 \mu \mathrm{g} \mathrm{m}^{-3}$, and only $4.1 \%$ of those cities satisfied air quality standards in 2013. Since then, the Chinese government has promoted the National Air Pollution Control Plan to relieve this situation and successfully reduced the concentration of air pollutants, especially $\mathrm{PM}_{2.5}$. In the last four years, the national annual average $\mathrm{PM}_{2.5}$ concentrations decreased from $72 \mu \mathrm{g} \mathrm{m}^{-3}$ (in 2013) to $62 \mu \mathrm{g} \mathrm{m}^{-3}$ (in 2014), $55 \mathrm{~g} \mathrm{~m} \mathrm{~m}^{-3}$ (in 2015) and $47 \mu \mathrm{g} \mathrm{m}^{-3}$ (in 2016) (MEE, 2013, 2014, 2015, 2016).

Fine particles $\left(\mathrm{PM}_{2.5}\right)$ directly reduce solar radiation, leading to a decrease in the surface temperature of up to $1 \mathrm{~K}$ (Im et al., 2012; Hu and Liu, 2017). The temperature decrease also depends on $\mathrm{PM}_{2.5}$ 's chemical composition, which determines whether the particles only scatter light or also absorb it. As sulfate aerosols are purely scattering, the surface temperatures decrease when the sulfate concentrations increase (Qian and Giorgi, 2000; Harris and Highwood, 2011; Solomon et al., 2011). Black carbon is the atmospheric aerosols' main absorbing component and may reduce the cooling effect of aerosols as it can warm the atmosphere at the top of the boundary layer (Schult et al., 1997; Chang and Park, 2004; Wu et al., 2008). A large number of studies show that aerosol properties also have significant regional characteristics $(\mathrm{Wu}$ et al., 2013; Jia et al., 2015). Zhuang et al. (2014) investigated the aerosol particles of Nanjing based on observational data and pointed out that the aerosol particles in the urban center showed strong absorbing ability, while those in the suburban area had a strong scattering ability. The inherently different $\mathrm{PM}_{2.5}$ loads and compositions between the urban center and suburban area resulted in different radiation forcing (Zhuang et al., 2014, 2015), thus causing different effects on the surface temperature in these two regions.

Although various investigations focused on the aerosols' radiative forcing and climate effects, the regional impact of $\mathrm{PM}_{2.5}$ on UHIs is rarely investigated. Cao et al. (2016) found increased longwave radiation emitted by an aerosol layer would intensify the nighttime UHI according to remote sensing temperature data from 39 cities in China. Our previous study showed that differences in the $\mathrm{PM}_{2.5}$ loads in the urban center and suburban region reduced the daytime UHI intensity based on one-year observational data and numerical simulations in Nanjing (Wu et al., 2014, 2017). However, a long-term observational data analysis is still lacking. The $\mathrm{PM}_{2.5}$ reductions resulting from the Air Pollution Control Plan in the last four years could possibly cause a daytime increase and a nighttime decrease of UHIs. This means that the control plan may introduce a "seesaw pattern" to the UHIs in daytime and nighttime.

To comprehensively understand the $\mathrm{PM}_{2.5}$ impact on UHIs, we use long-term and multi-site observational data as well as numerical modeling in this paper. In particular, we investigate how the Air Pollution Control Plan affects the UHI intensity when reducing the air pollution in the Yangtze River Delta. The Yangtze River Delta (YRD) is not only one of the most developed regions in China with the highest city density and urbanization level but also the largest adjacent metropolitan areas in the world (Hu et al., 2009). In the last four years, the air pollutant concentrations in the YRD have been reduced by the Air Pollution Control Plan as the regional average $\mathrm{PM}_{2.5}$ concentration decreased from $67 \mu^{-3} \mathrm{~g} \mathrm{~m}^{-3}$ (in 2013) to $60 \mu \mathrm{g} \mathrm{m}^{-3}$ (in 2014), $53 \mu \mathrm{g} \mathrm{m}^{-3}$ (in 2015) and $46 \mu \mathrm{g} \mathrm{m}^{-3}$ (in 2016) (MEE, 2013, 2014, 2015, 2016). Four megacities with spreading urbanization as Nanjing (NJ), Hangzhou (HZ), Shanghai (SH) and Hefei (HF) in the YRD are taken to be the target cities, and we analyze a record of four-year surface temperatures and $\mathrm{PM}_{2.5}$ concentrations.

In the following sections, $T_{\mathrm{UHI}}$ (the surface UHI intensity) refers to the difference in the surface temperature at the urban and suburban stations. A larger $T_{\mathrm{UHI}}$ corresponds to a more intense UHI effect. We define $\Delta T_{\mathrm{UHI}}$ (the difference in $T_{\mathrm{UHI}}$ between the simulations with and without the air pollution control) as the change in the UHI intensity due to the Air Pollution Control Plan, quantifying the control plan's effect on UHI intensity. A positive value of $\Delta T_{\mathrm{UHI}}$ indicates that the UHI intensity is strengthened by the conduct of the control plan. The variable $\Delta T$ is used to represent the surface temperature changes with and without the control plan, with positive values of $\Delta T$ representing a higher surface temperature when the control plan is present. $\Delta S W$ refers to the downward shortwave radiation changes at the surface caused by the control plan, and a positive value means that the conduction of the plan results in the surface receiving more solar radiation in the daytime due to the decrease of $\mathrm{PM}_{2.5}$ concentration. We also define $\Delta L W$ as the TOA outgoing longwave radiation changes with and without the control plan; a positive value indicates more radiation emitted by the atmosphere, which means the earth-atmosphere system would cool down in the night.

\section{METHODOLOGY}

\section{Observational Data}

This study period is from $1^{\text {st }}$ of January 2014 to $31^{\text {st }}$ of December 2017. The hourly surface temperature data and the hourly $\mathrm{PM}_{2.5}$ concentration data were collected separately from the Meteorological Bureau and the Environmental Monitoring Center of NJ, HZ, SH and HF. All the $\mathrm{PM}_{2.5}$ sites are located near the surface temperature observation sites, and the distances between them are small, so we only show surface temperature sites of the four cities in this paper. The altitude variation within the YRD is small, and therefore the altitude impact on the observational data could be ignored. The urban center sites and the suburban sites in these cities are all located in places with no heavy industrial emission sources within $30 \mathrm{~km}$. However, the urban sites are close to major roads with heavy traffic and large population aggregations. All suburban sites are nearly 30-40 km away from the urban centers and inhabited by a small population. The suburban site of SH is near the ocean, while other suburban cities from other cities are surrounded by crop fields without impact of mountains or ocean. Compared to the suburban sites, there are more artificial buildings and less green spaces in urban areas. The specific locations of all the sites are shown in Fig. 1 and were used in the model experiments. The urban sites in NJ, HZ, SH and HF are marked as U_NJ, U_HZ, U_SH and U_HF, and suburban sites are represented by S_NJ, S_HZ, S_SH and S_HF. 


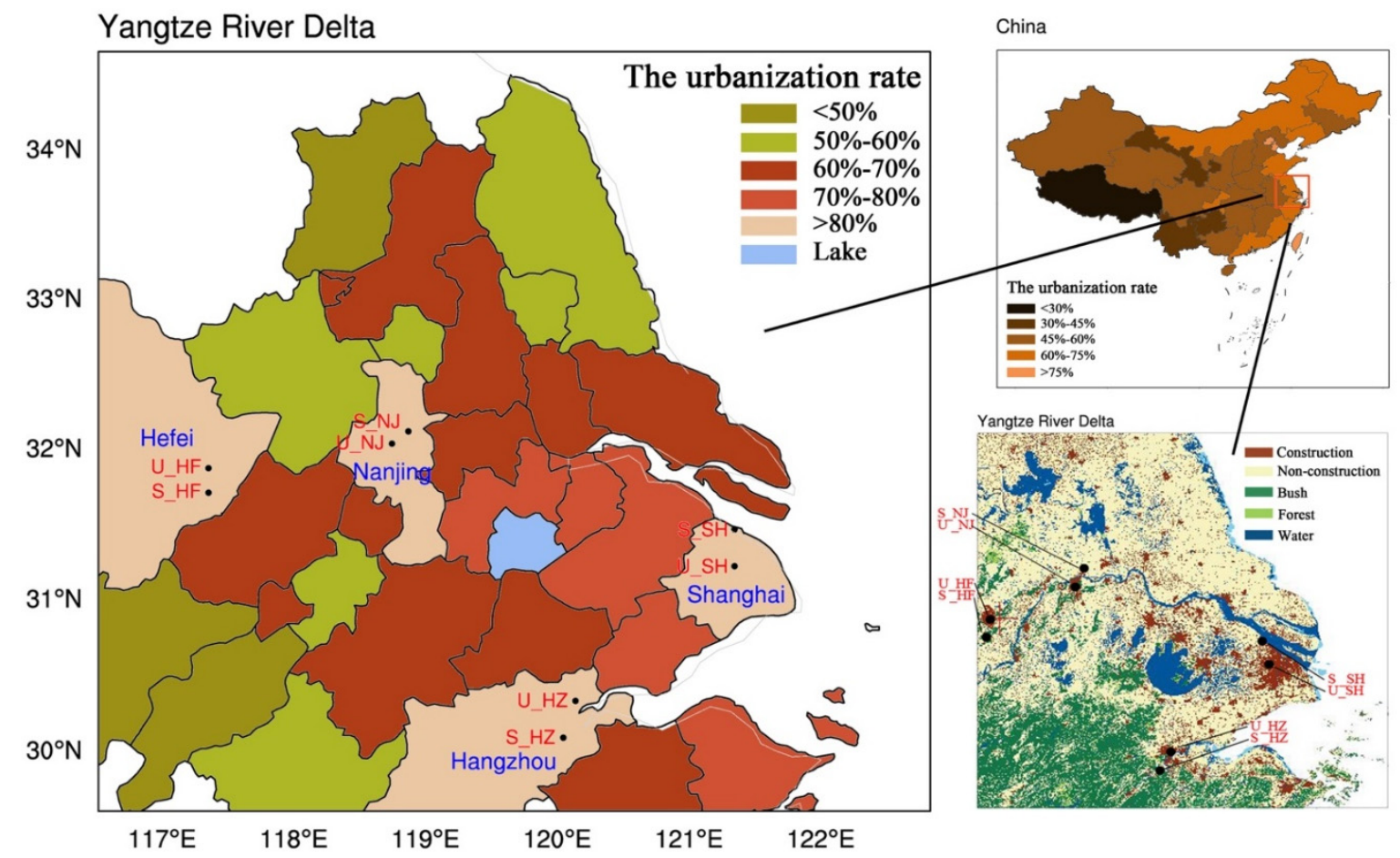

Fig. 1. Locations of the urban stations (U_NJ, U_HZ, U_SH and U_HF) and the suburban stations (S_NJ, S_HZ, S_SH and

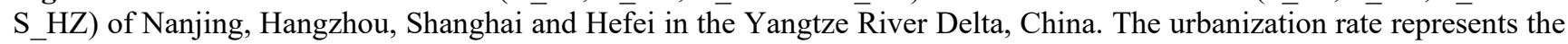
proportion of urban population to total population.

\section{Numerical Experiments}

The Weather Research and Forecasting (WRF) model coupled with Chemistry version 3.7 (Grell et al., 2005; Skamarock, 2006; Skamarock and Klemp, 2008) is an online modeling system and was used for this paper to investigate the influences of the Air Pollution Control Plan on UHIs. The WRF-Chem uses a non-hydrostatic dynamical core and includes emissions of gas-phase species and aerosols, gasphase chemical transformations, photolysis and gas-particle partitioning for inorganic and organic aerosol species as well as the removal of gas-phase and aerosol species by wet and dry deposition.

In this study, the physics scheme was chosen to be Purdue Lin microphysics scheme (Lin et al., 1983), and the cumulus scheme was Grell-Devenyi (Grell and Dévényi, 2002). The shortwave parameterization was NOAA Goddard (Chou et al., 2001), and the longwave parameterization is RRTM (Mlawer et al., 1997). The gas-phase chemistry was based on the Carbon-Bond Mechanism version $Z$ with 67 species and 164 reactions in a lumped structure approach that classifies organic compounds according to their internal bond types (Zaveri and Peters, 1999). The Fast-J scheme was used to derive the rates for photolytic reactions (Wild et al., 2000). The aerosol module was the Model for Simulating Aerosol Interactions and Chemistry (MOSAIC), including sulfate, methane sulfonate, nitrate, chloride, carbonate, ammonium, sodium, BC, OC, liquid water and other inorganic mass (Zaveri et al., 2008). Both biogenic and anthropogenic contributions to emissions were included. Biogenic emissions were calculated online using Guenther's scheme (Guenther et al., 1993, 1994). Anthropogenic emissions were supplied from an offline resource, based on the work of MEIC (Multi-resolution Emission Inventory for China) including the species $\mathrm{SO}_{2}$, $\mathrm{NO}_{\mathrm{x}}, \mathrm{CO}, \mathrm{NH}_{3}, \mathrm{NMVOC}, \mathrm{PM}_{2.5}, \mathrm{PM}_{10}, \mathrm{BC}, \mathrm{OC}$ and $\mathrm{CO}_{2}$.

The model was configured with three one-way nested domains using grid resolutions of $81 \mathrm{~km}, 27 \mathrm{~km}$ and $9 \mathrm{~km}$. The NCEP global reanalysis dataset with a $1^{\circ} \times 1^{\circ}$ resolution was used to supply initial meteorological fields and boundary conditions.

To investigate the impact of the control plan on UHI intensities, two sets of experiments were conducted for January (winter) and July (summer) 2015 in the YRD. The air pollutant emissions were set as the anthropogenic emissions of 2012 in the first experiment. The second experiment used approximately 50\% anthropogenic emissions of 2012 to represent the anthropogenic emissions in 2015 which were reduced by the control plan. The following paragraph will show that the $50 \%$ reduction for the pollutants is a reasonable assumption. Therefore, the differences of the UHI intensities of the two experiments quantify the effect of the control plan on the UHI.

Fig. 2(a) shows a quantitative comparison of the hourly observed and simulated $\mathrm{PM}_{2.5}$ concentrations at the urban stations and suburban stations in NJ, HZ, SH and HF for January and July in 2015. The HF suburban site showed some missing data during July 2015. Although the simulated monthly average $\mathrm{PM}_{2.5}$ concentrations at U_NJ and S_NJ are over-predicted by approximately $10 \mu \mathrm{g} \mathrm{m}^{-3}$, the hourly variations of all the sites are well simulated when compared to the observations of the two months, with fine differences less than $3 \mu \mathrm{g} \mathrm{m}^{-3}$. In particular, the peak values of $\mathrm{PM}_{2.5}$ concentrations in January and July are well reproduced at all 
the sites. To further validate the model, the hourly simulation results of the $\mathrm{UHI}$ intensities in $\mathrm{NJ}, \mathrm{HZ}, \mathrm{SH}$ and $\mathrm{HF}$ are evaluated against in situ observations for January and July in Fig. 2(b). The hourly variations of the UHI intensities at $\mathrm{NJ}$ and SH are well captured by the model in the two months. Although the model underestimates the UHI intensity values somewhat at $\mathrm{HZ}$ at the end of July, it still captures the hourly variations of the UHI intensities at HZ in January and July. However, the UHI intensities at HF are underestimated in January by nearly $1 \mathrm{~K}$ and over-predicted by approximately $1.2 \mathrm{~K}$ in July. In conclusion, despite some discrepancies between observed and simulated results, the $50 \%$ reduced
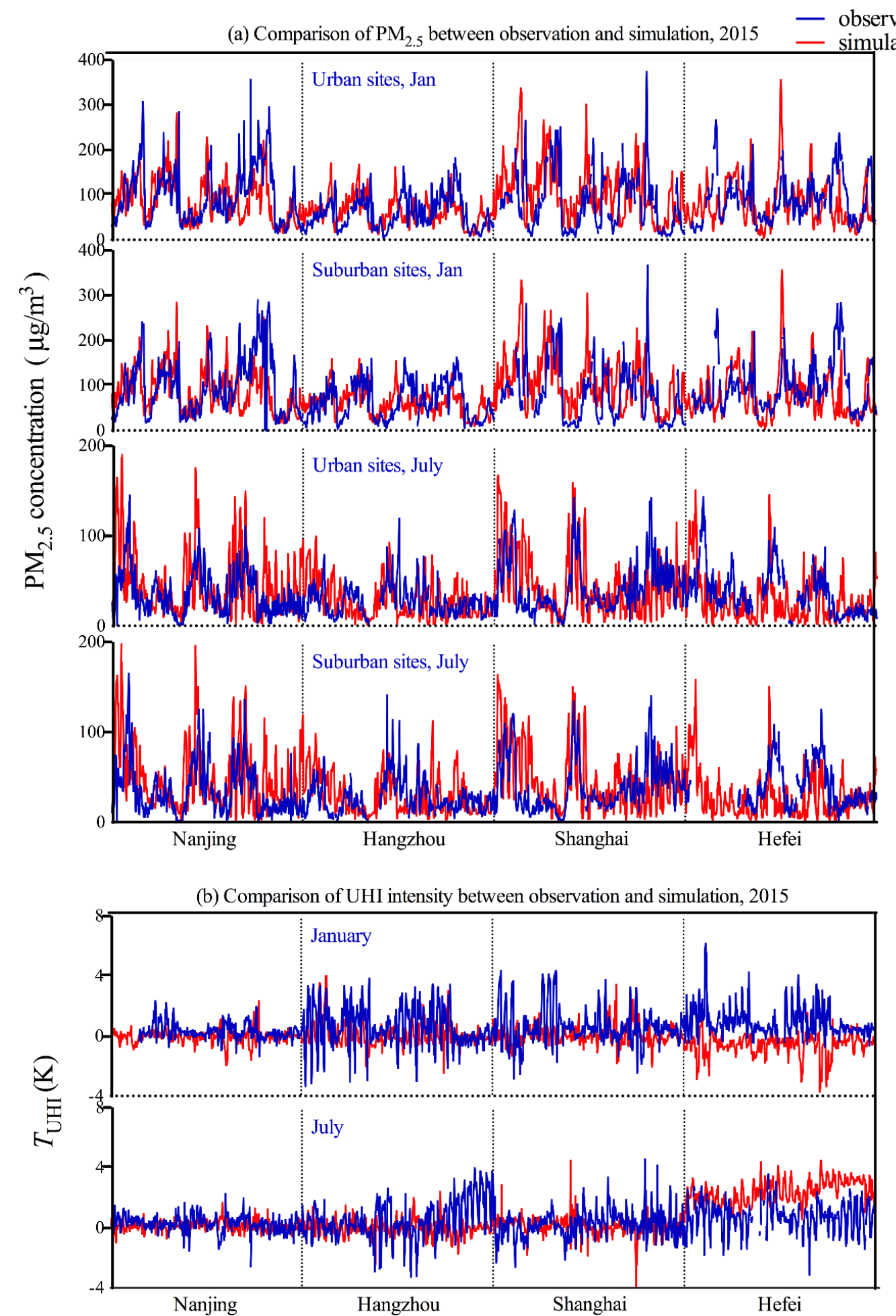

Fig. 2. Comparison of hourly average observed and simulated (a) $\mathrm{PM}_{2.5}$ concentrations and (b) UHI intensity values for Nanjing, Hangzhou, Shanghai and Hefei in the Yangtze River Delta, 2015. 
anthropogenic emissions in 2012 seems reasonable to represent the anthropogenic emissions in 2015, and the model results are credible for further analysis.

\section{RESULTS}

\section{Long-term Analysis of Observed PM2.5 and UHI Intensity} Trends from 2014 to 2017

Fig. 3 shows a long-term analysis of observed $\mathrm{PM}_{2.5}$ concentrations and UHI intensity data using one-hour sampling intervals. Despite some missing observational data in Figs. 3(b)-3(d) and 3(h), Figs. 3(a)-3(d) show a decline of $\mathrm{PM}_{2.5}$ concentrations in the target cities of the YRD - not only the annual average values but also the peak values. Of all four cities, HF always suffers the most severe pollution, but since 2014 the annual average $\mathrm{PM}_{2.5}$ concentration reduced by $26.56 \mu \mathrm{g} \mathrm{m}^{-3}$. NJ used to have higher $\mathrm{PM}_{2.5}$ levels than HZ and SH in 2014, but the control plan finally made NJ, HZ and SH have similar $\mathrm{PM}_{2.5}$ concentrations with an annual average value of around $35 \mu \mathrm{g} \mathrm{m}^{-3}$ in 2017. The annual $\mathrm{PM}_{2.5}$ levels in NJ, HZ, SH and $\mathrm{HF}$ in 2017 are approximately reduced by $48.36 \%, 28.25 \%, 29.41 \%$ and $32.5 \%$ when compared to the 2014 values, which indicates a significant improvement of air quality of China. The detailed statistical data of $\mathrm{PM}_{2.5}$ concentrations of these four cities from 2014 to 2017 is shown in the supplementary information. Usually, the $\mathrm{PM}_{2.5}$ concentrations in the urban center were higher than in the suburbs.

In contrast to the decreased $\mathrm{PM}_{2.5}$ pollution levels, the UHI intensity increased from 2014 to 2017 in the YRD as shown in Figs. 3(e)-3(h). As the annual average value of $T_{\mathrm{UHI}}$ would balance the characteristics of UHI phenomenon and may not reflect the inter-annual variability well, we define the annual frequency of UHI as the proportion of $T_{\mathrm{UHI}}$ greater than zero as a metric for the UHI intensities in the YRD. HF had the smallest UHI frequency with highest $\mathrm{PM}_{2.5}$ level in 2014 of the four cities, but the UHI frequency in HF increased rapidly to $17.19 \%$ with $23.4 \%$ decreased
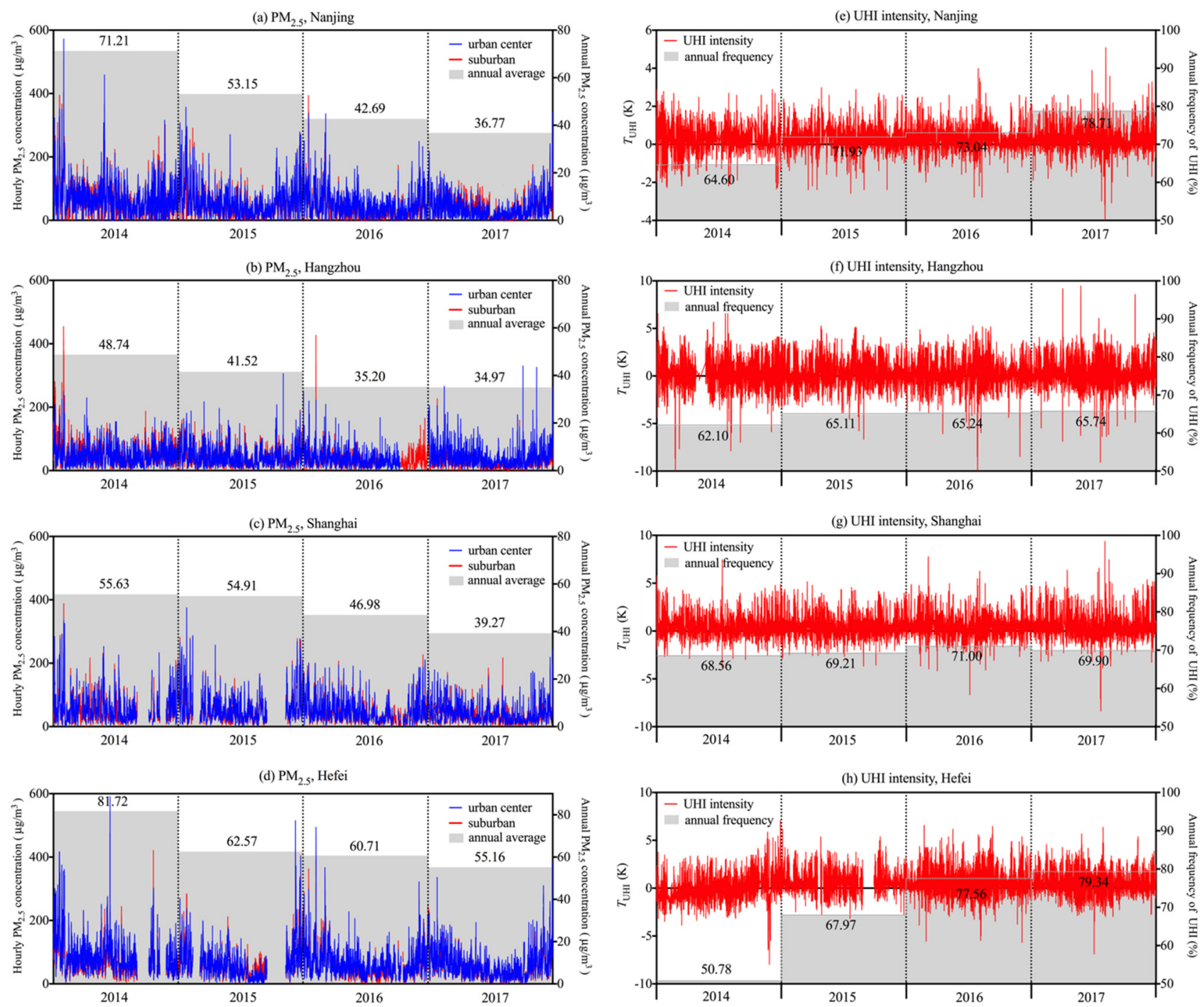

Fig. 3. Time series of $\mathrm{PM}_{2.5}$ concentration and urban heat island intensity values from 2014 to 2017 in the Yangtze River Delta: time series of $\mathrm{PM}_{2.5}$ concentration in (a) Nanjing, (b) Hangzhou, (c) Shanghai and (d) Hefei; time series of urban heat island intensity in (e) Nanjing, (f) Hangzhou, (g) Shanghai and (h) Hefei. 
$\mathrm{PM}_{2.5}$ concentration in 2015. The UHI frequency in $\mathrm{NJ}$ strengthened much more than that in $\mathrm{SH}$ and $\mathrm{HZ}$ every year with the higher decrease of $\mathrm{PM}_{2.5}$ concentrations. The risings of the annual UHI frequencies in Figs. 3(e)-3(h) appeared slower in 2016 and 2017 when compared to that in 2015, which is consistent with the falling rates of $\mathrm{PM}_{2.5}$ level in Figs. 3(a)-3(d). However, the UHI intensities are also dependent on other factors such as landscape and surface albedo; thus we cannot expect that the UHI intensities of NJ, $\mathrm{SH}, \mathrm{HZ}$ and $\mathrm{HF}$ respond linearly to reductions in $\mathrm{PM}_{2.5}$, but the mechanisms are similar in all four locations. We hypothesize that the Air Pollution Control Plan causes the increase in $\mathrm{UHI}$ intensities in the YRD as a response to $\mathrm{PM}_{2.5}$ levels. To investigate this hypothesis, we will compare the observed UHI intensities under different $\mathrm{PM}_{2.5}$ levels. At the same time, we will use the WRF-Chem model to do numerical experiments and further analyze the effect of $\mathrm{PM}_{2.5}$ on UHI intensities.

\section{Observed PM2.5 Effects on UHIs}

To further investigate the hypothesis, we classified the hourly values of the UHI intensities into three groups according to the observed $\mathrm{PM}_{2.5}$ concentrations in the four urban centers, representing light $\left(\mathrm{PM}_{2.5}\right.$ concentrations less than $\left.35 \mu \mathrm{g} \mathrm{m}^{-3}\right)$, medium $\left(\mathrm{PM}_{2.5}\right.$ concentrations greater than or equal to $35 \mu \mathrm{g} \mathrm{m}^{-3}$ and less than or equal to $75 \mu \mathrm{g} \mathrm{m}^{-3}$ ) and heavy $\mathrm{PM}_{2.5}$ levels $\left(\mathrm{PM}_{2.5}\right.$ concentrations greater than $\left.75 \mu \mathrm{g} \mathrm{m}^{-3}\right)$. Since the concentrations of $\mathrm{PM}_{2.5}$ decreased with the pollution control plan, we do not have any data points in the category "heavy $\mathrm{PM}_{2.5}$ levels" in $\mathrm{HZ}$ and $\mathrm{SH}$ for the year 2017 (Figs. 4(b-4) and 5(a-4)). In Figs. 4 and 5, negative $T_{\mathrm{UHI}}$ values represent that the suburban region is warmer than the urban region, and the positive values represent that the urban region is warmer.

In Figs. 4 and 5, the diurnal cycles of $T_{\mathrm{UHI}}$ are compared for the three $\mathrm{PM}_{2.5}$ levels defined above. For the same $\mathrm{PM}_{2.5}$ levels, the $T_{\mathrm{UHI}}$ values vary between cities, with higher positive values in $\mathrm{SH}$ and $\mathrm{HF}$ compared to NJ and HZ. For the light, medium and heavy $\mathrm{PM}_{2.5}$ levels in $\mathrm{HZ}$ as well as for the medium and heavy $\mathrm{PM}_{2.5}$ levels in $\mathrm{NJ}$ and $\mathrm{SH}$, we found similar characteristics as maximum values occur at nights (1-1.5 $\mathrm{K}$ in $\mathrm{HZ}, 0.5-0.8 \mathrm{~K}$ in $\mathrm{NJ}$ and $0.5-1.5 \mathrm{~K}$ in $\mathrm{SH}$ ), and minimum values occur during the afternoons $(-0.5-0.5 \mathrm{~K}$ in $\mathrm{HZ},-0.1-0.3 \mathrm{~K}$ in $\mathrm{NJ}$ and $0-0.5 \mathrm{~K}$ in $\mathrm{SH})$. The peak values at night result from the smaller wind speed and the inversion layer; they work together to inhibit the turbulent transport of the near-surface heat in the urban center to the upper air.

The $T_{\mathrm{UHI}}$ values under light $\mathrm{PM}_{2.5}$ levels in NJ have small diurnal variation with values of less than $0.5 \mathrm{~K}$. At $\mathrm{SH}, T_{\mathrm{UHI}}$ is lowest in the mornings $(0 \mathrm{~K})$ with values of about $0.5 \mathrm{~K}$ in later hours. HF is different from $\mathrm{NJ}, \mathrm{HZ}$ and $\mathrm{SH}$ in that it shows the maximum $T_{\mathrm{UHI}}$ values occurring in the afternoons $(1-1.5 \mathrm{~K})$ and the minimum values occurring before dawn $(-1-0 \mathrm{~K})$ under light, medium and heavy $\mathrm{PM}_{2.5}$ levels. This regulation may come from the terrace topography of $\mathrm{HF}$ when compared to other three cities, which need further investigation.

For any given year, as the $\mathrm{PM}_{2.5}$ levels decrease from heavy to light, the UHI intensities increase during the daytime and decrease at nighttime in the four cities. The $T_{\mathrm{UHI}}$ values for light $\mathrm{PM}_{2.5}$ levels in $\mathrm{SH}$ and $\mathrm{HF}$ in 2014 do not follow this pattern for some of the hours. This can be explained by only a few data points entering the calculation for $T_{\mathrm{UHI}}$, so the light levels in Figs. 5(a-1) and 5(b-1) are not representative. To compare the trend in $T_{\mathrm{UHI}}$ under different $\mathrm{PM}_{2.5}$ levels, we averaged the daytime values and the nighttime values separately. We define 07:00-18:00 as daytime and 18:00-07:00 as nighttime. From 2014 to 2017, the averaged daytime UHI intensities strengthened by $0.2-0.6 \mathrm{~K}$ in NJ, by $0.2 \mathrm{~K}-0.5 \mathrm{~K}$ in $\mathrm{HZ}$, by $0.3-1 \mathrm{~K}$ in $\mathrm{SH}$ and by $0.5-$ $1 \mathrm{~K}$ in $\mathrm{HF}$ when the $\mathrm{PM}_{2.5}$ levels varied from heavy to light level. However, the nighttime UHI intensities are reduced by $0.5-0.8 \mathrm{~K}$ in $\mathrm{NJ}, 0.2-0.5 \mathrm{~K}$ in $\mathrm{HZ}, 0.3-1 \mathrm{~K}$ in $\mathrm{SH}$ and $0.5-1 \mathrm{~K}$ in $\mathrm{HF}$ at the same time. The impact of $\mathrm{PM}_{2.5}$ levels on UHI intensities vary between different cities, but the same pattern can be observed as the UHI intensities was strengthened in the daytime and reduced at night from 2014 to 2017 when the $\mathrm{PM}_{2.5}$ level became lighter, due to the implementation of the control plan. To distinguish the $T_{\mathrm{UHI}}$ variation due to the $\mathrm{PM}_{2.5}$ concentrations but not from the ambient meteorological conditions, we take different seasons into consideration. The impact of $\mathrm{PM}_{2.5}$ levels on $\mathrm{UHI}$ intensities shows the consistent regulation in different seasons from 2014 to 2017. In all seasons, the UHI intensities were strengthened in the daytime and reduced at night when the $\mathrm{PM}_{2.5}$ levels changed from heavy to light level. The detailed figures are shown in the supplementary information. The correlations between the $T_{\mathrm{UHI}}$ values and the corresponding $\mathrm{PM}_{2.5}$ differences of the urban and suburban sites $\left(\Delta \mathrm{PM}_{2.5}\right)$ of $\mathrm{NJ}, \mathrm{HZ}, \mathrm{SH}$ and HF from 2014 to 2017 are shown in Fig. 6. The $\mathrm{PM}_{2.5}$ values range from 0 to 60 . Negative correlations between the UHI intensity and $\triangle \mathrm{PM}_{2.5}$ were found for all the four cities for the daytime: As $\Delta \mathrm{PM}_{2.5}$ increased, the UHI intensity tended to decrease in the daytime. Oppositely, positive correlations between these two quantities were found during the nighttime: As $\Delta \mathrm{PM}_{2.5}$ increased, the UHI intensity tended to increase. The linear regression coefficients (r) of each panel in Fig. 6 are given in Table 1 as $-0.148,-0.102,-0.103$ and -0.121 in the daytime and $0.083,0.107,0.128$ and 0.098 in the nighttime of NJ, HZ, SH and HF. A higher positive value of $r$ represents the stronger positive correlation and vice versa. The results from separating the data in day and night groups confirm our hypothesis that the air pollution control could not only cause increases of the UHI intensities in the daytime but also result in decreases of the UHI intensities during the nighttime. We name this the "seesaw effect" because the Air Pollution Control Plan impacts the UHI intensities in the daytime and nighttime in opposite ways: Increases of UHI intensities in the daytime occur alongside reductions of the UHI intensities during the nighttime.

\section{Simulated Effects on Surface Temperature with the Air Pollution Control Plan}

As described in the section "Methodology," WRF-Chem simulations were conducted to investigate the effects of the control plan on the surface temperature in the YRD. Two experiments, one with 2012 anthropogenic emissions and one with 50\% reduced 2012 anthropogenic emissions (representing 
(a-1) 2014, Nanjing

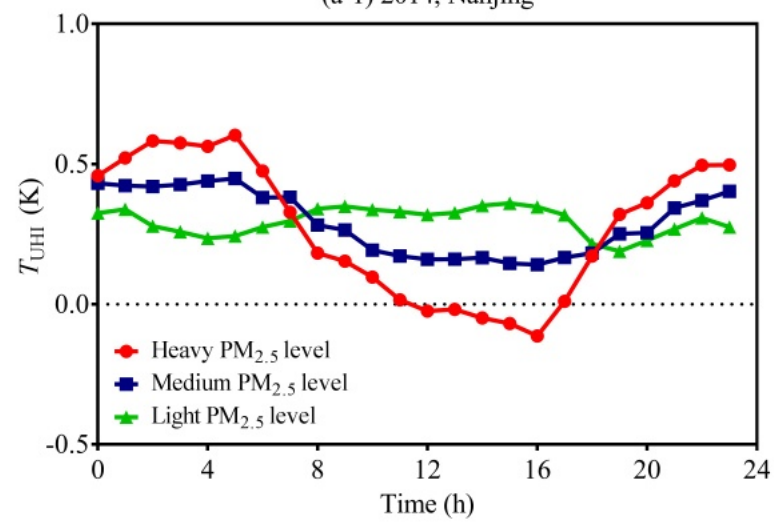

(a-2) 2015, Nanjing

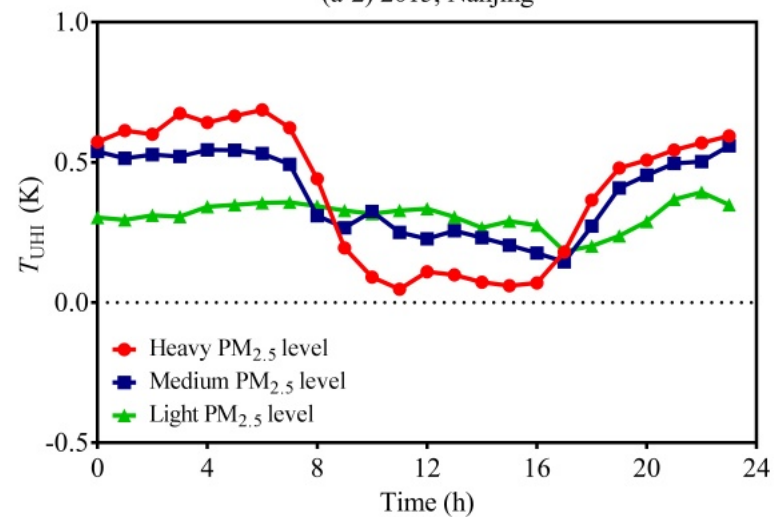

(a-3) 2016, Nanjing

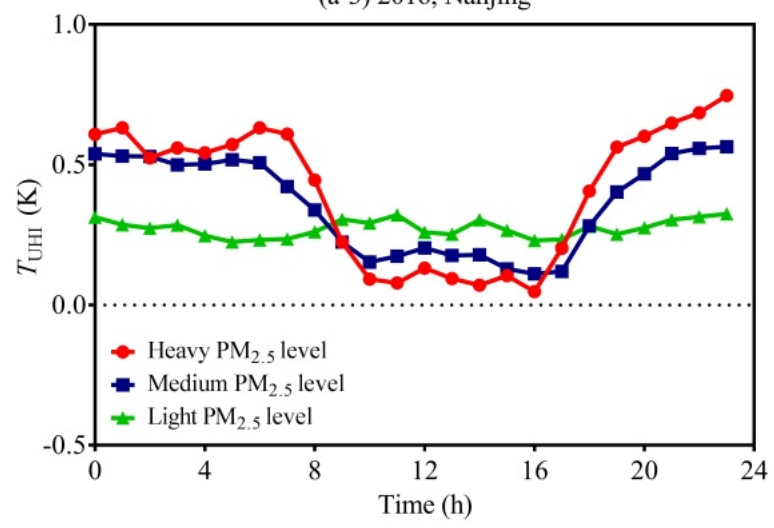

(a-4) 2017, Nanjing

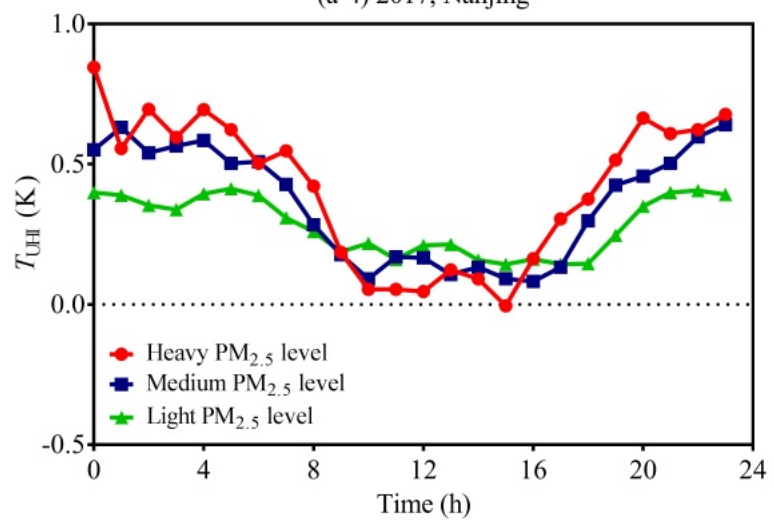

(b-1) 2014, Hangzhou

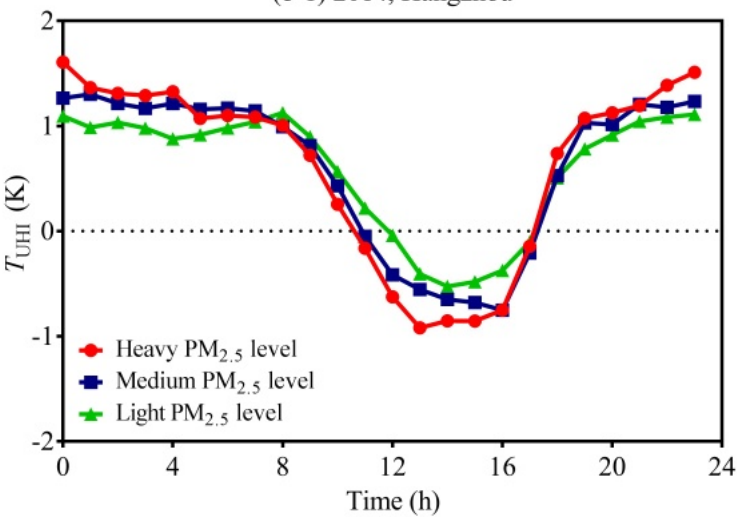

(b-2) 2015, Hangzhou

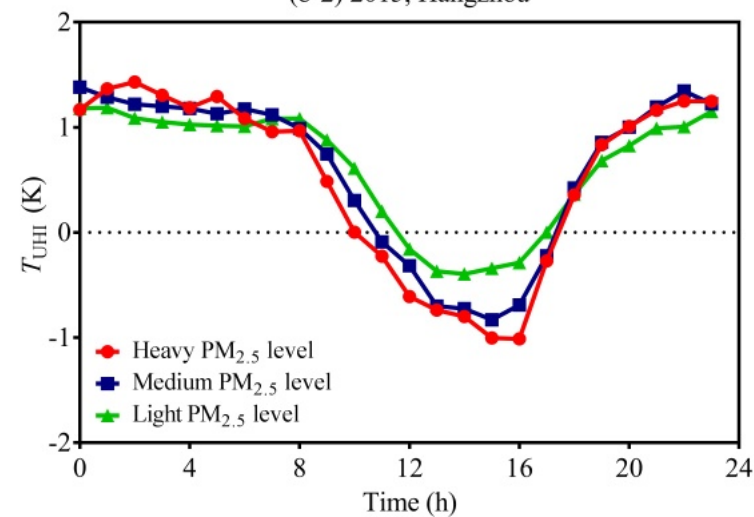

(b-3)2016,Hangzhou

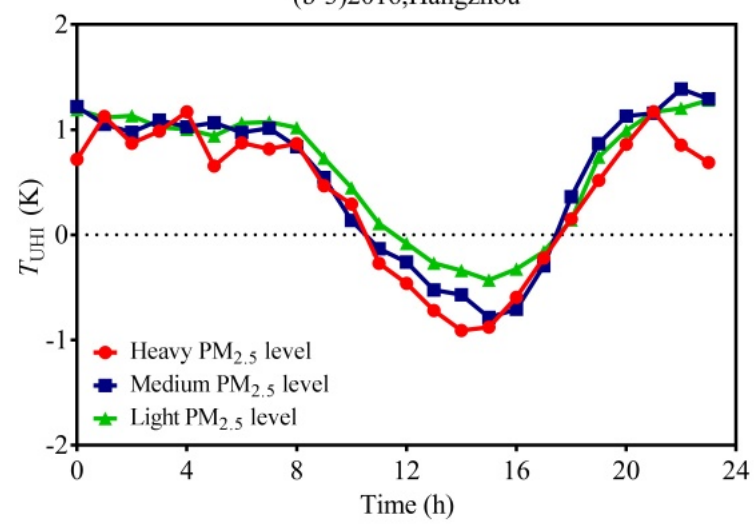

(b-4) 2017, Hangzhou

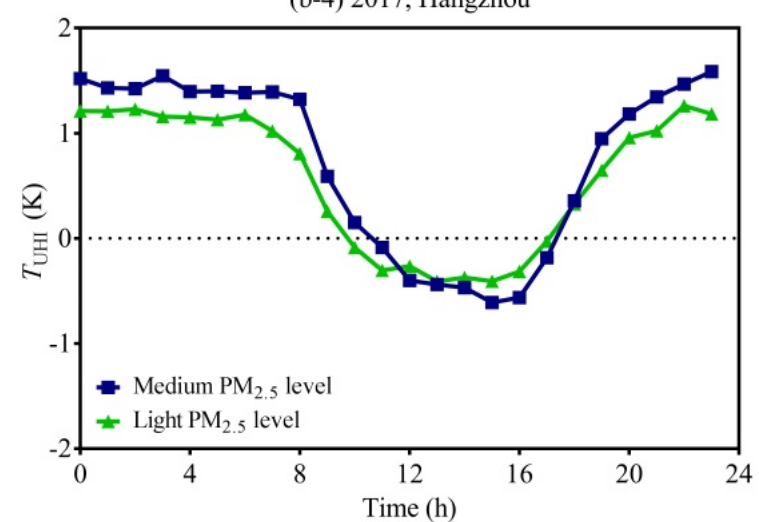

Fig. 4. Observed diurnal variations of UHI intensities for different $\mathrm{PM}_{2.5}$ levels in the YRD, 2014-2017: (a-1) 2014, (a-2) 2015, (a-3) 2016 and (a-4) 2017 in NJ; (b-1) 2014, (b-2) 2015, (b-3) 2016 and (b-4) 2017 in HZ. 
(a-1) 2014, Shanghai

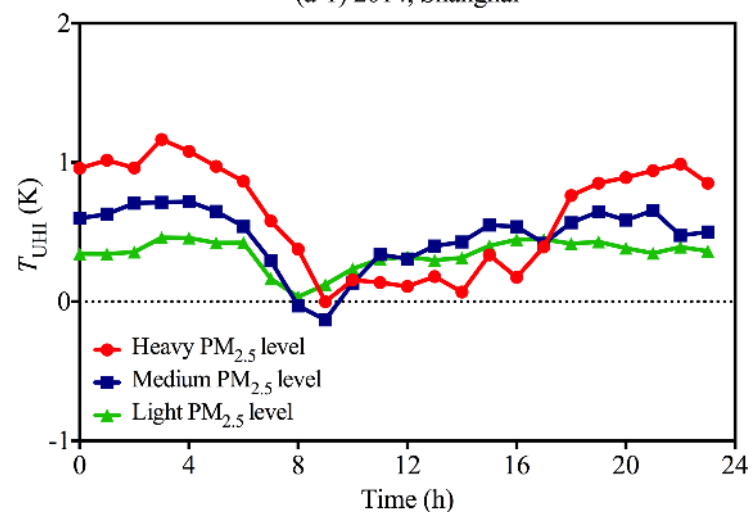

(a-2) 2015, Shanghai

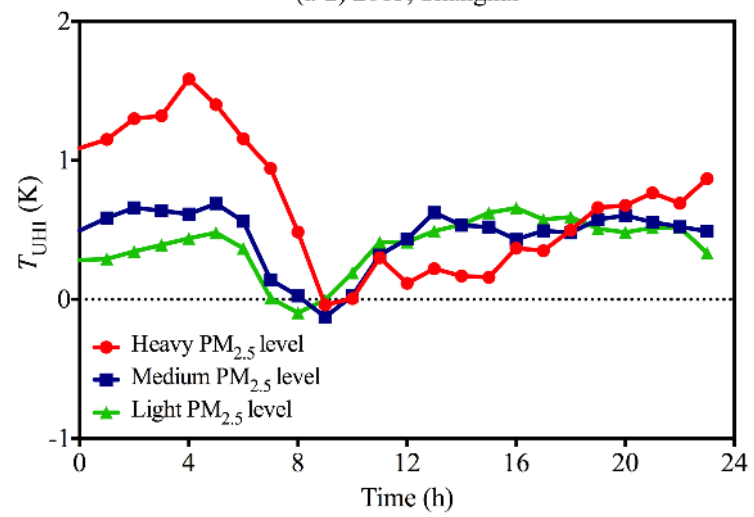

(a-3) 2016, Shanghai

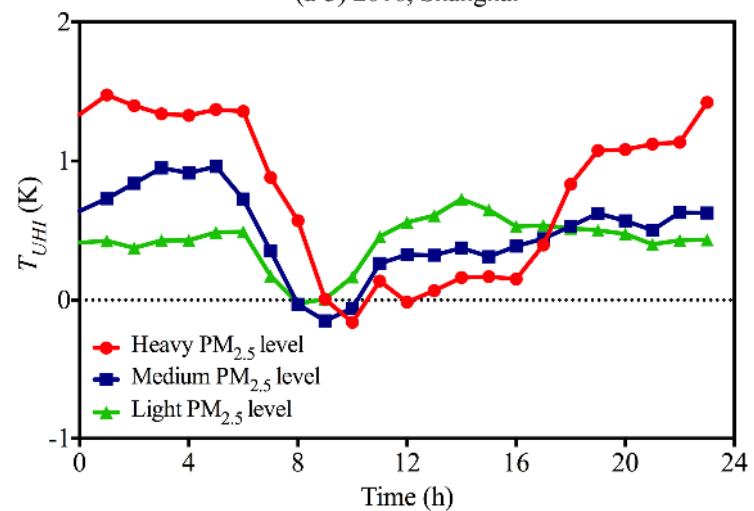

(a-4) 2017, Shanghai

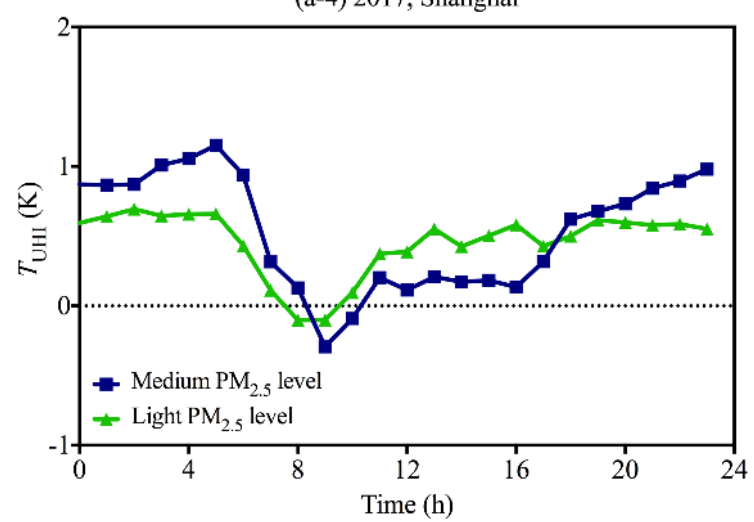

(b-1) 2014, Hefei

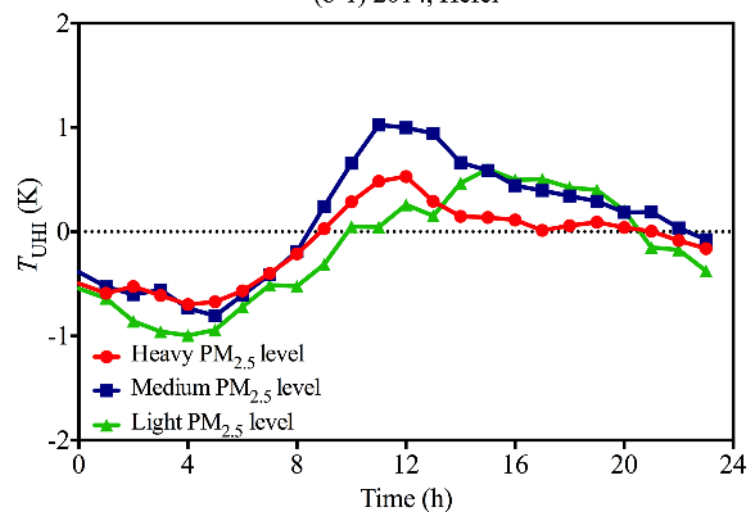

(b-2) 2015, Hefei

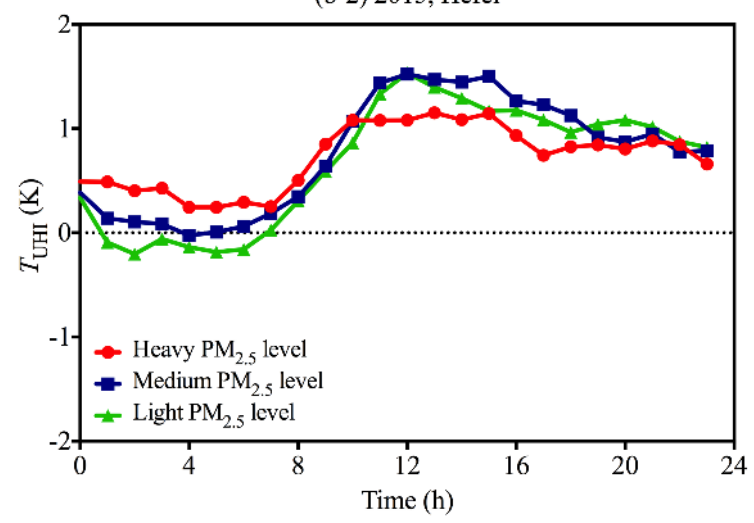

(b-3) 2016, Hefei

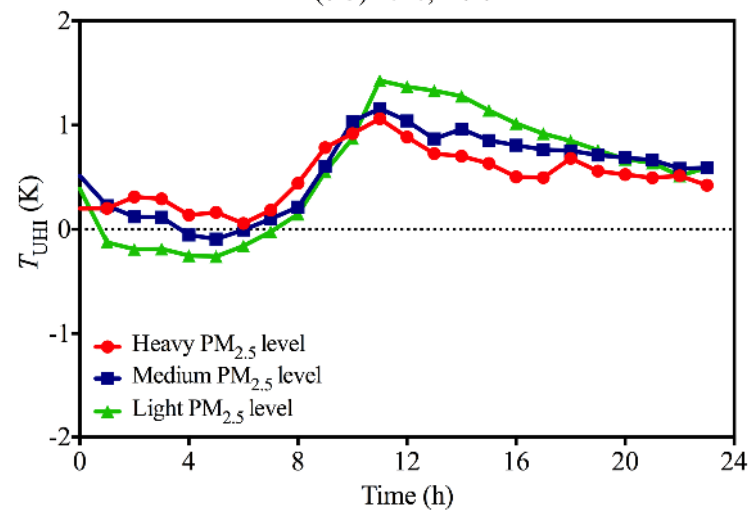

(b-4) 2017, Hefei

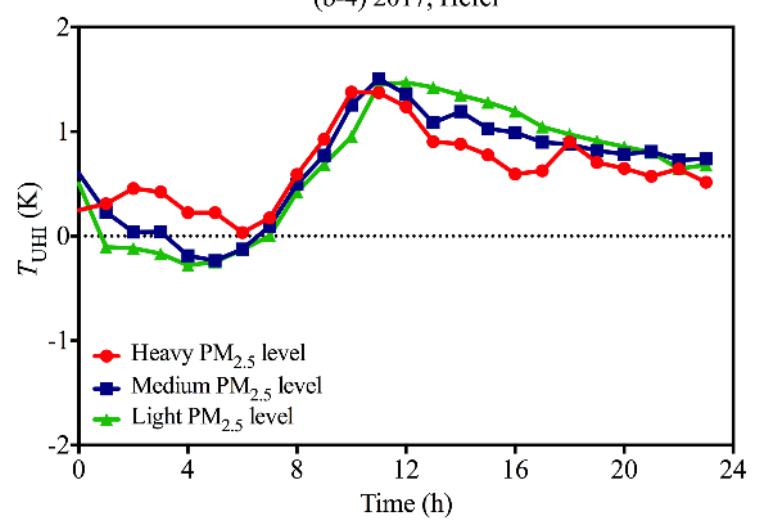

Fig. 5. Observed diurnal variations of UHI intensities for different $\mathrm{PM}_{2.5}$ levels in the YRD, 2014-2017: (a-1) 2014, (a-2) 2015, (a-3) 2016 and (a-4) 2017 in SH; (b-1) 2014, (b-2) 2015, (b-3) 2016 and (b-4) 2017 in HF. 

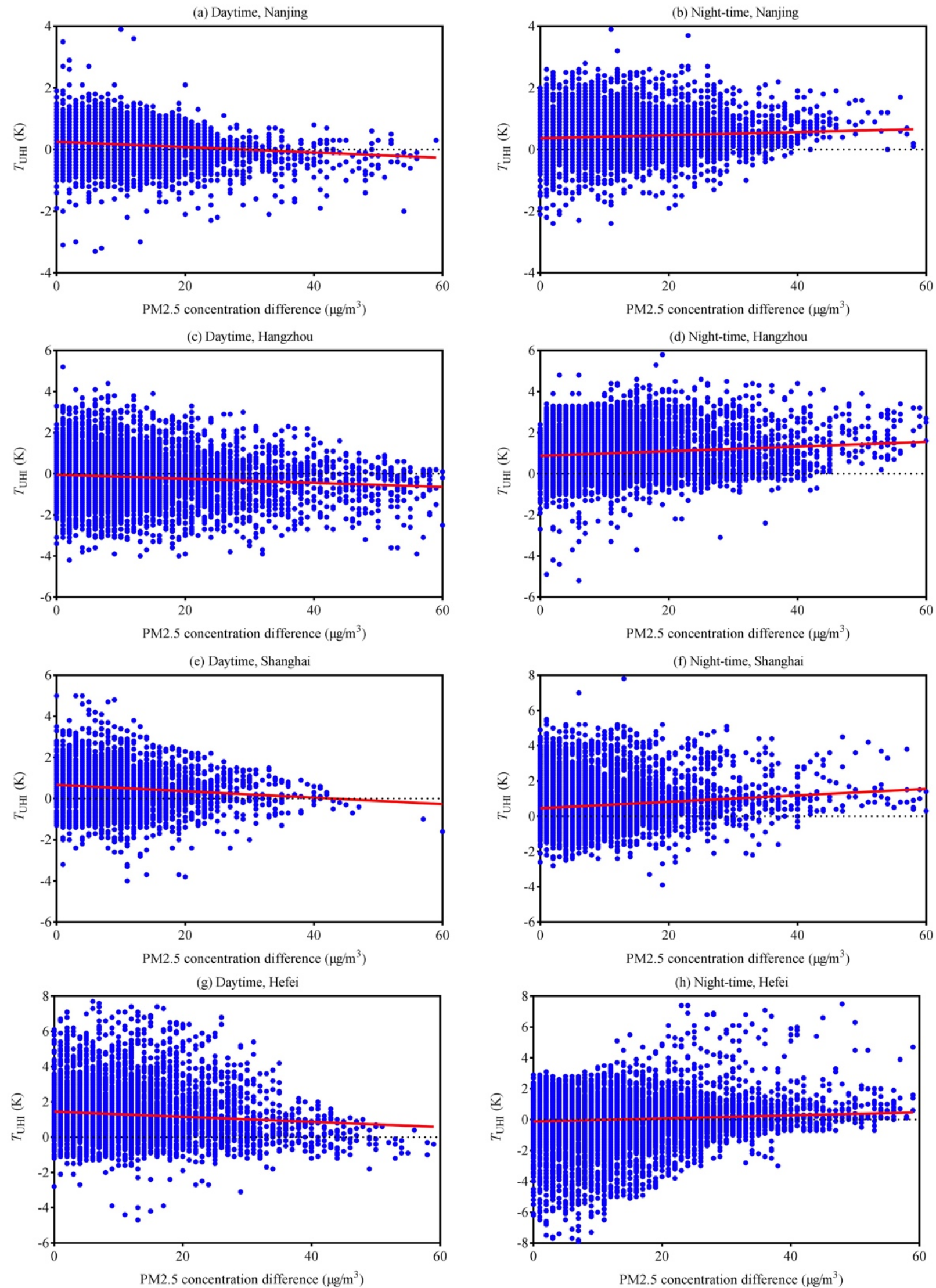

Fig. 6. Correlations between the observed UHI intensities and $\mathrm{PM}_{2.5}$ concentration differences of Nanjing, Hangzhou, Shanghai and Hefei in daytime and nighttime, 2014-2017: (a) daytime and (b) nighttime in Nanjing; (c) daytime and (d) nighttime in Hangzhou; (e) daytime and (f) nighttime in Shanghai; (g) daytime and (h) nighttime in Hefei. 
Table 1. Linear correlation coefficients of each panel in Fig. 6.

\begin{tabular}{lllll}
\hline \multirow{2}{*}{ City } & \multirow{2}{*}{} & \multicolumn{2}{c}{ Pearson test } \\
\cline { 5 - 5 } Nanjing & Daytime & -0.148 & $<$-value (two-tailed) & significant \\
\multirow{3}{*}{ Hangzhou } & Nighttime & 0.083 & $<0.0001$ & Yes \\
& Daytime & -0.102 & $<0.0001$ & Yes \\
\multirow{2}{*}{ Shanghai } & Nighttime & 0.107 & 0.0059 & Yes \\
& Daytime & -0.103 & 0.0023 & Yes \\
\multirow{2}{*}{ Hefei } & Nighttime & 0.128 & $<0.0001$ & Yes \\
& Daytime & -0.121 & $<0.0001$ & Yes \\
& Nighttime & 0.098 & 0.0002 & Yes \\
\hline
\end{tabular}

anthropogenic emissions in 2015), were carried out. The differences of the surface $\mathrm{PM}_{2.5}$ concentrations, the downward shortwave radiation $(\triangle S W)$ at the surface, the TOA outgoing longwave radiations $(\Delta L W)$ and the surface temperatures $(\Delta T)$ were taken to assess the role of the Air Pollution Control Plan on the surface temperature. As $\mathrm{PM}_{2.5}$ has negative surface radiative forcing and increases cloud condensation nuclei, the $\Delta S W, \Delta L W$ and $\Delta T$ are expected to be greater than 0 with lower $\mathrm{PM}_{2.5}$ loadings (Susskind and Molnar, 2011; Im et al., 2012).

The horizontal distribution of the monthly averaged surface $\mathrm{PM}_{2.5}$ concentration differences caused by the pollution control plan over the YRD from the output of the lowest model layer is shown in Figs. 7(a)-7(b). The control plan reduced the $\mathrm{PM}_{2.5}$ concentrations of the YRD by $90-120 \mu \mathrm{g} \mathrm{m}^{-3}$ in January and $40-70 \mu \mathrm{g} \mathrm{m}^{-3}$ in July. A more unstable atmosphere during the summer leads to the increased amount of precipitation and better ventilation conditions, resulting in increased surface $\mathrm{PM}_{2.5}$ removal by wet deposition (Wu et al., 2017). Due to that, $\mathrm{PM}_{2.5}$ concentrations in summer are always lower than winter.

Due to these factors, the $\mathrm{PM}_{2.5}$ concentration levels are different for the 2012 base case in January and July, leading to the differences in the monthly averaged surface $\mathrm{PM}_{2.5}$ concentrations for January and July in 2015 after the control plan. However, the distribution patterns of $\mathrm{PM}_{2.5}$ concentration differences are similar in summer and winter in that the largest decreases of $\mathrm{PM}_{2.5}$ are found in the urban centers of NJ, HZ, SH and HF as these are the areas with the highest concentrations for fine particles (MEE, 2013, 2014) compared to the suburban regions.

The $\Delta S W$ and $\Delta L W$ caused by the decreases of $\mathrm{PM}_{2.5}$ are not only dependent on the reduction value of $\mathrm{PM}_{2.5}$ but also on the amount of energy that the earth received from the sun. As the earth received more solar radiation from the sun in July than January, the $\Delta S W$ and $\Delta L W$ are higher in July even though the $\mathrm{PM}_{2.5}$ change is lower for that month (Figs. 7(c)$7(\mathrm{f})$ ). During the daytime, the pollution control plan enhanced the surface downward solar radiation (SW) in the YRD ranging from $4-16 \mathrm{~W} \mathrm{~m}^{-2}$ in January and $8-36 \mathrm{~W} \mathrm{~m}^{-2}$ in July by reducing $\mathrm{PM}_{2.5}$ levels, leading to the increases of surface temperature (Figs. 7(g) and 7(h)). The TOA outgoing longwave radiation (LW) is the energy radiating from the earth to space and causes radiative cooling of the atmosphere. Increased LW cooling results from the decreases of $\mathrm{PM}_{2.5}$ and causes a decrease of surface temperature in the nighttime, which will be discussed in the next section.

The monthly averaged surface temperature change $(\Delta T)$ caused by the air pollution plan (Figs. $7(\mathrm{~g})$ and $7(\mathrm{~h})$ ) results from the changes of $\mathrm{SW}$ and $\mathrm{LW}$, and $\Delta S W$ plays the dominant role, which means that Figs. 7(g) and 7(h) represents the daytime effect of the pollution control plan. Owing to the seasonal variation of the $\mathrm{PM}_{2.5}$ differences and $\Delta S W, \Delta T$ is generally higher in July and lower in January over the YRD. However, the atmosphere is a system with complex feedbacks. For example, the changes in surface temperature by $\mathrm{PM}_{2.5}$ will change the moisture transport and result in precipitation feedbacks, which in turn affect the surface temperature. Therefore, the horizontal distribution of $\Delta T$ cannot be expected to always look similar to the distribution of the $\mathrm{PM}_{2.5}$ differences, but the $\Delta T$ gradient around the $\mathrm{PM}_{2.5}$ sources can be found in Figs. 7(a)-7(b) and. 7(g)-7(h). We need to compare the $\Delta T$ of the urban areas to the $\Delta T$ of the suburban areas in the four cities to determine the impact of the pollution control plan on the UHI. Figs. 7(g) and 7(h) show the same results that the $\Delta T$ values in urban centers of $\mathrm{NJ}$, $\mathrm{HZ}$, SH and HF (nearly $0.32 \mathrm{~K}$ ) are higher than that in the suburban areas (nearly $0.16 \mathrm{~K}$ ), indicating the strengthened UHI intensity caused by the control plan.

\section{UHI Intensity Seesaw by the Air Pollution Control Plan}

According to the observational results, the UHI intensity is strengthened during the day and weakened in the night as the $\mathrm{PM}_{2.5}$ concentrations decrease. From the last section, the inhomogeneous warming effect on the surface temperature can indeed be found across the YRD (Figs. 7(g)-7(h)). But the daytime effects dominate over the nighttime effects, and therefore the nighttime effects are not visible in the monthly averages of UHI intensities. Next, we quantify the diurnal variations of $\Delta T_{\mathrm{UHI}}$ caused by the presence of the pollution control plan, shown in Fig. 8.

During the daytime, the surface temperature was increased due to the increased SW caused by the decreased $\mathrm{PM}_{2.5}$ levels. Since the reduction of $\mathrm{PM}_{2.5}$ loadings in the urban center is consistently larger than that in the suburban areas of the four cities, the $\Delta T$ was larger in the urban centers, which explains the strengthened UHI intensity when the pollution control plan was included in the simulations. Thus, $\Delta T_{\mathrm{UHI}}$ values of the target cities in the YRD are always greater than 0 during the daytime and vary with locations. The negative values of $\Delta T_{\mathrm{UHI}}$ during the nighttime were found as well, which is consistent with the observed analysis in 

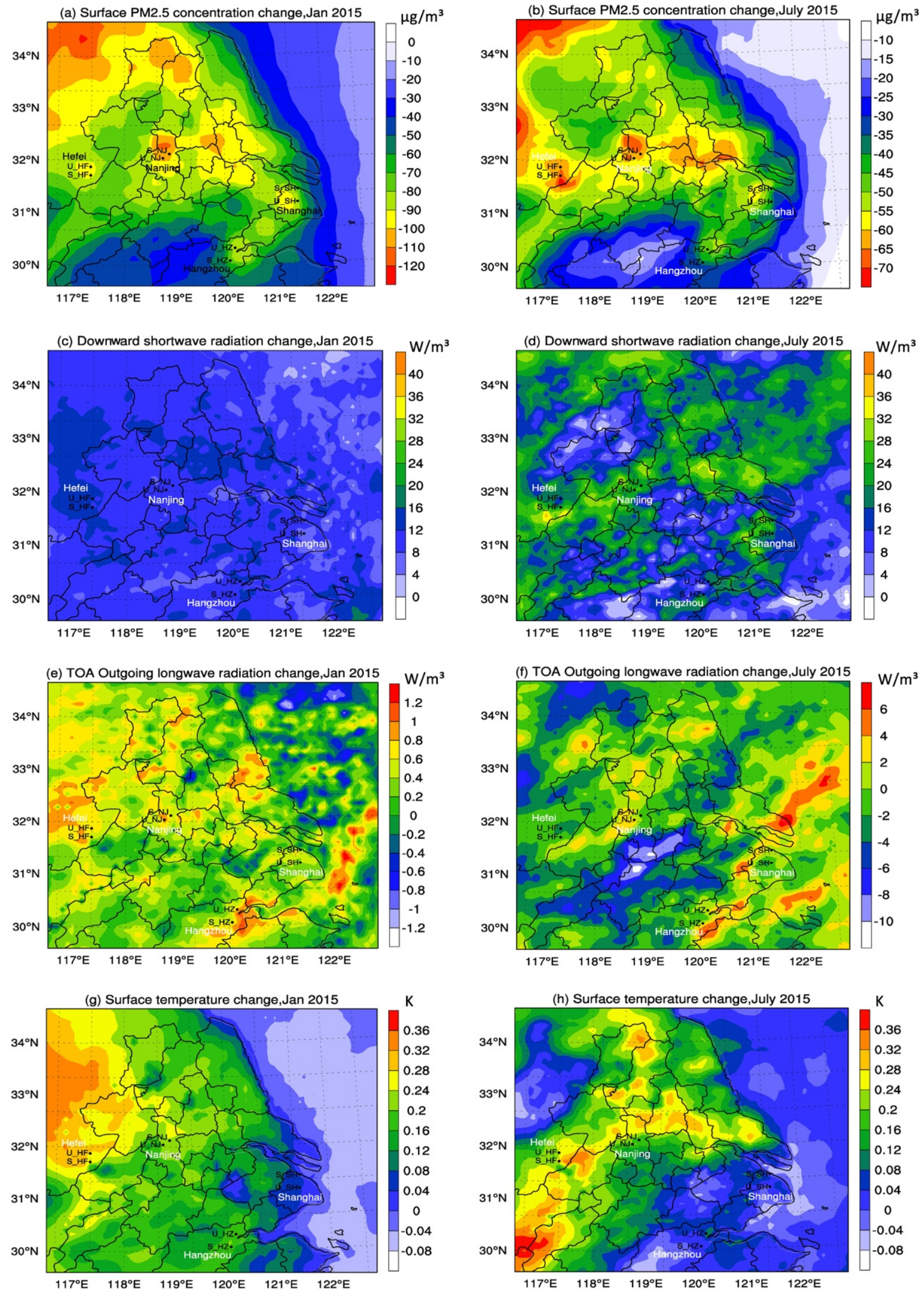

Fig. 7. Monthly averaged surface $\mathrm{PM}_{2.5}$ concentration change, surface downward shortwave radiation change $(\triangle S W)$, TOA outgoing longwave radiation change $(\Delta L W)$ and surface temperature change $(\Delta T)$ at a 2-m height due to the Air Pollution Control Plan in the YRD, 2015: surface $\mathrm{PM}_{2.5}$ concentration change in (a) January and (b) July; $\Delta S W$ in (c) January and (d) July; $\Delta L W$ in (e) January and (f) July; $\Delta T$ in (g) January and (h) July. 

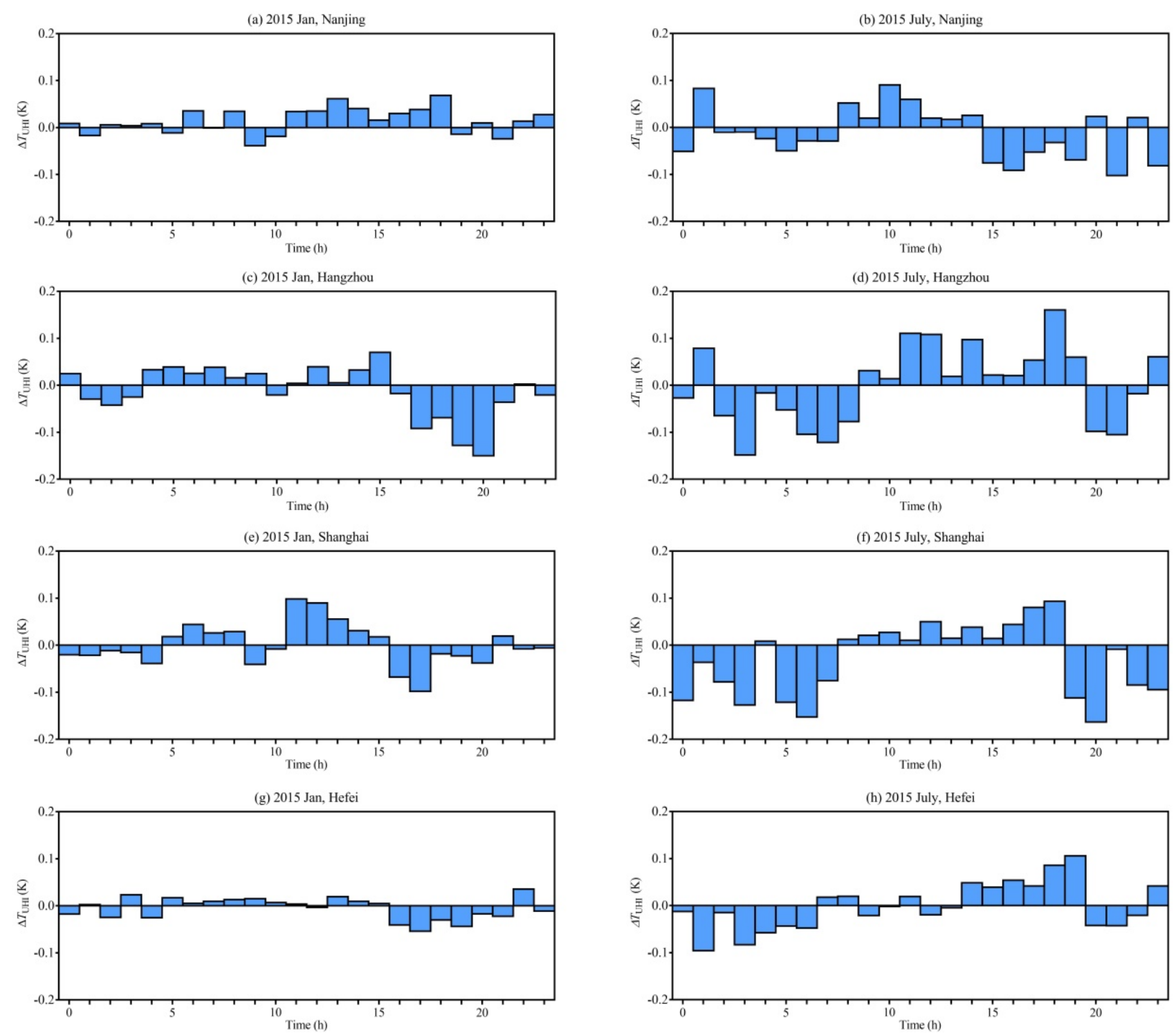

Fig. 8. Monthly average of the diurnal cycles of the simulated changes in UHI intensities $\left(\Delta T_{\mathrm{UHI}}\right)$ due to air pollution control in the Yangtze River Delta, 2015: $\Delta T_{\mathrm{UHI}}$ of Nanjing in (a) January and (b) July, Hangzhou in (c) January and (d) July, Shanghai in (e) January and (f) July and Hefei in (g) January and (h) July.

Figs. 4-6. The reduction of $\mathrm{PM}_{2.5}$ levels due to the control plan increased the LW radiation (Figs. 7(e)-7(f)), leading to the decreased UHI intensity in the nighttime. Cao et al. (2016) confirmed that the high levels of $\mathrm{PM}_{2.5}$ would enhance the UHI intensities over China, which is consistent with our results.

The magnitude of the $\Delta T_{\mathrm{UHI}}$ was larger in July than in January. The seasonal variations of $\Delta T_{\mathrm{UHI}}$ depend on both the available solar radiation and the differences of $\mathrm{PM}_{2.5}$ concentrations. Although the $\mathrm{PM}_{2.5}$ levels' difference in July is smaller as we have discussed above, the $\Delta S W$ and $\Delta L W$ both have higher values in July. As a result, $\Delta T_{\mathrm{UHI}}$ shows a higher magnitude in July than in January in all the four cities, which means the "seesaw effect" of the control plan is more prominent in summer. This effect on UHI intensities also varies across the locations. In January, the absolute values of $\Delta T_{\mathrm{UHI}}$ is always lowest in HF $(0.02-0.05 \mathrm{~K})$ but highest in $\mathrm{SH}(0.1-0.12 \mathrm{~K})$, which means that the control plan impacts $\mathrm{SH}$ most but HF least. HZ has the largest absolute values of $\Delta T_{\mathrm{UHI}}$ in July $(0.16-0.18 \mathrm{~K})$, and $\mathrm{SH}$ has slightly smaller absolute $\Delta T_{\mathrm{UHI}}$ values $(0.12-0.16 \mathrm{~K})$, and the control plan still affected HF least $(0.1 \mathrm{~K})$.

\section{DISCUSSION}

Our study reveals that the Air Pollution Control Plan of 2013 reduced $\mathrm{PM}_{2.5}$ concentrations in the YRD by nearly $30 \%$ between 2014 and 2017 and increased the intensity of the UHIs during the day (by up to $1 \mathrm{~K}$, based on the observational data) while decreasing it (by up to $1 \mathrm{~K}$ ) during the night - a phenomenon we named the "seesaw effect." According to our simulations, the reduction in the $\mathrm{PM}_{2.5}$ load increased the diurnal downward surface shortwave radiation by up to $16 \mathrm{~W} \mathrm{~m}^{-2}$ and $36 \mathrm{~W} \mathrm{~m}^{-2}$ during January and July, respectively, leading to warmer surface temperatures in the 
YRD. The nocturnal outgoing TOA longwave radiation also increased as the $\mathrm{PM}_{2.5}$ decreased, resulting in cooler surface temperatures. The inhomogeneous decrease in the $\mathrm{PM}_{2.5}$ unevenly affected surface temperatures, thus influencing the intensity of the UHIs, although the simulated effects of the control plan on the $\mathrm{PM}_{2.5}$ concentration were more evident in the urban centers than the suburban areas of all four studied cities for January and July. The simulated $\Delta S W$ and $\Delta L W$ values for the YRD were larger during July than January, which is consistent with the $\Delta T_{\mathrm{UHI}}$, whereas the UHI intensity was affected less during January than July. Comparing the simulated $\Delta T_{\mathrm{UHI}}$ values for $\mathrm{NJ}, \mathrm{HZ}, \mathrm{SH}$ and $\mathrm{HF}$, we conclude that the control plan affected $\mathrm{SH}$ and $\mathrm{HZ}$ the most and HF the least.

The $\mathrm{PM}_{2.5}$ concentration and UHI intensity are significant reference signals in an urban environment. We showed that the reduction in $\mathrm{PM}_{2.5}$ intensifies the UHI effect during the daytime and weakens it during the nighttime. Heavy air pollution in China may have masked the UHI phenomenon and other symptoms of "city disease" during recent decades; hence, the change in contamination level must be treated as a potential factor when analyzing the UHI in a city. Measures such as establishing urban ventilation corridors to mitigate the UHI effect and other urban climate issues, which have been exposed by the implementation of the Air Pollution Control Plan, should be taken.

\section{ACKNOWLEDGEMENTS}

This work was supported by the National Key Basic Research Development Program of China (2016YFC0203303, 2017YFC0209803 and 2016YFC0208504) and the National Natural Science Foundation of China (91544230, 41575145 and 41621005). We appreciate the Nanjing, Hangzhou, Shanghai and Hefei Meteorological Bureau for the temperature data and the Nanjing, Hangzhou, Shanghai and Hefei Environmental Monitoring Center for the $\mathrm{PM}_{2.5}$ concentration data. We thank Prof. Xuhui Lee from Yale University for his useful comments.

\section{SUPPLEMENTARY MATERIAL}

Supplementary data associated with this article can be found in the online version at http://www.aaqr.org.

\section{REFERENCES}

Agarwal, M. and Tandon, A. (2010). Modeling of the urban heat island in the form of mesoscale wind and of its effect on air pollution dispersal. Appl. Math. Modell. 34: 2520 2530.

Cao, C., Lee, X., Liu, S., Schultz, N., Xiao, W., Zhang, M. and Zhao, L. (2016). Urban heat islands in China enhanced by haze pollution. Nat. Commun. 7: 12509.

Chang, L.S. and Park, S.U. (2004). Direct radiative forcing due to anthropogenic aerosols in East Asia during April 2001. Atmos. Environ. 38: 4467-4482.

Chou, M.D., Suarez, M.J., Liang, X.Z., Yan, M.M.H. and Cote, C. (2001). A thermal infrared radiation parameterization for atmospheric studies. NASA. Tech. Memo. No. 104606, 19: 1-55.

Grell, G.A. and Dévényi, D. (2002). A generalized approach to parameterizing convection combining ensemble and data assimilation techniques. Geophys. Res. Lett. 29: 381-38-4.

Grell, G.A., Peckham, S.E., Schmitz, R., McKeen, S.A., Frost, G., Skamarock, W.C. and Eder, B. (2005). Fully coupled "online" chemistry within the WRF model. Atmos. Environ. 39: 6957-6975.

Guenther, A.B., Zimmerman, P.R., Harley, P.C., Monson, R.K. and Fall, R. (1993). Isoprene and monoterpene emission rate variability: Model evaluations and sensitivity analyses. J. Geophys. Res. 98: 12609-12617.

Guenther, A., Zimmerman, P. and Wildermuth, M. (1994). Natural volatile organic-compound emission rate estimates for United-States woodland landscapes. Atmos. Environ. 28: 1197-1210.

Harris, B.M. and Highwood, E.J. (2011). A simple relationship between volcanic sulfate aerosol optical depth and surface temperature change simulated in an atmosphere-ocean general circulation model. J. Geophys. Res. 116: D05109.

Hjelmfelt, M.R. (2017). Numerical simulation of the effects of St. Louis on mesoscale boundary layer airflow and vertical air motion: Simulations of urban vs. non-urban effects. J. Appl. Meteorol. 21: 1239-1257.

Howard L. (1833). Climate of London deduced from meteorological observations. Harvey and Darton. pp: 124.

$\mathrm{Hu}, \mathrm{S}$. and Liu, H. (2017). Effects of $\mathrm{PM}_{2.5}$ on the urban radiation and air temperature in Hefei. J. Meteorol. Sci. 1: 78-85. (in Chinese with English Abstract)

Hu, Y., Ban, Y., Zhang, Q. and Liu, J. (2009). The trajectory of urbanization process in the Yangtze River delta during 1990 to 2005. 2009 Joint Urban Remote Sensing Event, Shanghai, China, 20-22 May 2009.

Im, U., Markakis, K., Koçak, M., Gerasopoulos, E., Daskalakis, N., Mihalopoulos, N., Poupkou, A., Kindap, T., Unal, A. and Kanakidou, M. (2012). Summertime aerosol chemical composition in the Eastern Mediterranean and its sensitivity to temperature. Atmos. Environ. 50: 164-173.

Jia H., Cheng, N., He Y., Chen, Y., Du, X. and Shan, X. (2015). Numerical Study on the characteristics of regional transport of $\mathrm{PM}_{2.5}$ in Shandong Province during Spring in 2014. Environ. Sci. 36: 2353-2360.

Jones, P., Groisman P.Y., Coughlan, M., Plummer, N., Wang, W. and Karl, T. (1990). Assessment of urbanization effects in time series of surface air temperature over land. Nature 347: 169-172.

Kaufman, Y.J., Tanré, D. and Boucher, O. (2002). A satellite view of aerosols in the climate system. Nature 419: 215223.

Liang, Z., Ma, M. and Du, G. (2014). Comparison of characteristics and trend analysis of atmospheric pollution in Beijing-Tianjin-Shijiazhuang, during 2003-2012. Environ. Eng. 12: 76-81.

Lin, C., Chen, F., Huang, J., Chen, W., Liou, Y., Chen, W. and Liu, S. (2008). Urban heat island effect and its impact 
on boundary layer development and land-sea circulation over northern Taiwan. Atmos. Environ. 42: 5635-5649.

Lin, Y., Farley, R.D. and Orville, H.D. (1983). Bulk parameterization of the snow field in a cloud model. $J$. Clim. Appl. Meteorol. 22: 1065-1092.

Manley, G. (1958). On the frequency of snowfall in metropolitan England. Q. J. R. Meteorolog. Soc. 84: 70-72.

MEE (Ministry of Ecology and Environment of the People's Republic of China) (2013). Bulletin on environmental conditions in China in 2013. http://www.zhb.gov.cn/hjzl/zg hjzkgb/lnzghjzkgb/201605/P020160526564151497131.pdf.

MEE (Ministry of Ecology and Environment of the People's Republic of China) (2014). Bulletin on environmental conditions in China in 2014. http://www.mep.gov.cn/hjzl/zg hjzkgb/lnzghjzkgb/201605/P020160526564730573906.pdf.

MEE (Ministry of Ecology and Environment of the People's Republic of China) (2015). Bulletin on environmental conditions in China in 2015. http://www.mep.gov.cn/hjzl/zg hjzkgb/lnzghjzkgb/201606/P020160602333160471955.pdf.

MEE (Ministry of Ecology and Environment of the People's Republic of China) (2016). Bulletin on Environmental Conditions in China in 2016. http://www.mep.gov.cn/hjzl/zg hjzkgb/lnzghjzkgb/201706/P020170605833655914077.pdf.

Mlawer, E.J., Taubman, S.J., Brown, P.D., Iacono, M.J. and Clough, S.A. (1997). Radiative transfer for inhomogeneous atmospheres: RRTM, a validated correlated-k model for the longwave. J. Geophys. Res. 102: 16663-16682.

Multi-resolution Emission Inventory for China, http://www.meicmodel.org/dataset-meic.html

Nabat, P., Somot, S., Mallet, M., Sevault, F., Chiacchio, M. and Wild, M. (2015). Direct and semi-direct aerosol radiative effect on the Mediterranean climate variability using a coupled regional climate system model. Clim. Dyn. 44: 1127-1155.

Oke, T.R. (2002). Boundary layer climates. Routledge.

Peterson, T.C., Gallo K.P., Lawrimore J., Owen T.W., Huang A. and McKittrick D.A. (1999). Global rural temperature trends. Geophys. Res. Lett. 26: 329-332.

Qian, Y. and Giorgi, F. (2000). Regional climatic effects of anthropogenic aerosols? The case of Southwestern China. Geophy. Res. Lett. 27: 3521-3524.

Schult, I., Feichter, J. and Cooke, W.F. (1997). Effect of black carbon and sulfate aerosols on the global radiation budget. J. Geophys. Res. 102: 30107-30117.

Skamarock, W.C. (2006). A description of the advanced research WRF version 3. NCAR Technical Notes, NCAR/TN-4751STR. 113: 7-25.

Skamarock, W.C. and Klemp, J.B. (2008). A time-split nonhydrostatic atmospheric model for weather research and forecasting applications. J. Comput. Phys. 227: 34653485.

Solomon, S., Daniel, J.S., Neely, R.R., Vernier, J.P., Dutton, E.G. and Thomason, L.W. (2011). The persistently variable "background" stratospheric aerosol layer and global climate change. Science 333: 866-870.

Susskind, J., Molnar, G. and Iredell, L. (2011). Contributions to climate research using the AIRS Science Team version-5 products. Proc. SPIE 8154, Infrared Remote Sensing and Instrumentation XIX, 8154: 91-94.
Wang, Y., Zhuang, G., Zhang, X., Huang, K., Xu, C., Tang, A., Chen J. and An, Z. (2006). The ion chemistry, seasonal cycle, and sources of $\mathrm{PM}_{2.5}$ and TSP aerosol in Shanghai. Atmos. Environ. 40: 2935-2952.

Wild, O., Zhu, X. and Prather, M. J. (2000). Fast-J: Accurate simulation of in-and below-cloud photolysis in tropospheric chemical models. J. Atmos. Chem. 37: 245-282.

Wu, D., Fung, J.C.H., Yao, T. and Lau, A.K.H. (2013). A study of control policy in the Pearl River Delta region by using the particulate matter source apportionment method. Atmos. Environ. 76: 147-161.

Wu, H., Wang, T., Fang, H., Ma, Y., Han, Y., Huang, S., Yao, Y. and Shi, J.Q. (2014). Impact of aerosol on the urban heat island intensity in Nanjing. Trans. Atmos. Sci. 37: 425-431.

Wu, H., Wang, T., Riemer, N., Chen, P., Li, M. and Li, S. (2017). Urban heat island impacted by fine particles in Nanjing, China. Sci. Rep. 7: 11422.

Wu, J., Fu, C., Xu, Y., Tang, J., Wang, W. and Wang, Z. (2008). Simulation of direct effects of black carbon aerosol on temperature and hydrological cycle in Asia by a Regional Climate Model. Meteorol. Atmos. Phys. 100: 179-193.

Xia, T., Wang, J., Song, K. and Da, L. (2014). Variations in air quality during rapid urbanization in Shanghai, China. Lands. Ecol. Eng. 10: 181-190.

Zaveri, R.A. and Peters, L.K. (1999). A new lumped structure photochemical mechanism for large-scale applications. $J$. Geophys. Res. 104: 30387-30415.

Zaveri, R.A., Easter, R.C., Fast, J.D. and Peters, L.K. (2008). Model for simulating aerosol interactions and chemistry (MOSAIC). J. Geophys. Res. 113: D13204.

Zhang, Y., Wen, X. and Jang, C. (2010). Simulating chemistry-aerosol-cloud-radiation-climate feedbacks over the continental U.S. using the online-coupled Weather Research Forecasting Model with chemistry (WRF/Chem). Atmos. Environ. 44: 3568-3582.

Zhao, L., Lee, X., Smith, R. B. and Oleson, K. (2014). Strong contributions of local background climate to urban heat islands. Nature 511: 216-219.

Zhong, S., Qian, Y., Zhao, C., Leung, R., Wang, H., Yang, B., Fan, J., Yan, H., Yang, X. and Liu, D. (2017). Urbanization-induced urban heat island and aerosol effects on climate extremes in the Yangtze River Delta region of China. Atmos. Chem. Phys. 17: 5439-5457.

Zhuang, B., Wang, T., Li, S., Liu, J., Talbot, R., Mao, H., Yang, X., Fu, C., Yin C., Zhu, J., Che, H., and Zhang, X. (2014). Optical properties and radiative forcing of urban aerosols in Nanjing, China. Atmos. Environ. 83: 43-52.

Zhuang, B., Wang, T., Liu, J., Ma, Y., Yin, C., Li, S., Xie, M., Han, Y., Zhu, J., Yang, X. and Fu, C. (2015). Absorption coefficient of urban aerosol in Nanjing, west Yangtze River Delta, China. Atmos. Chem. Phys. 15: 13633-13646.

Received for review, February 28, 2019 Revised, September 19, 2019 Accepted, October 15, 2019 